\title{
CARDIO SPECIFIC TROPONIN-I IN PATIENTS WITH VALVULAR HEART DISEASE
}

\author{
NAZMUN NAHAR ${ }^{1}$, BILQUIS ARA BEGUM ${ }^{2}$, MD. KHALAQUE UZ ZAMAN ${ }^{3}$, S.M.MASHUD ${ }^{4}$, MD. MOZAMMEL HOQUE ${ }^{5}$, \\ SULTANA PARVEEN ${ }^{1}$, ROKSANA YEASMIN ${ }^{1}$ \\ Department of Biochemistry, Ibrahim Medical college, Dhaka ${ }^{1}$; Department of Biochemistry, Ad-din Medical \\ College and Hospital, Dhaka ${ }^{2}$; Department of Cardiology, NICVD, Dhaka ${ }^{3}$; Chest Disease Hospital Dhaka ${ }^{4}$; \\ Department of Biochemistry, B.S.M.M.U, Dhaka ${ }^{5}$
}

\begin{abstract}
Valvular heart disease is a common cardiac disease in our country. The valvular heart disease which we face in our day to day hospital and private practice is due to chronic sequlae of rheumatic fever. In chronic rheumatic heart disease mitral valve is affected in more than $90 \%$ of cases and aortic valve is the next most frequently affected valve. This study was done to evaluate the association of Cardio specific Troponinl I (cTnl) and valvular heart disease. Cross sectional study was conducted among 60 valvular heart disease patients and 30 control groups. A structured questioner and checklist was used to collect data through face to face interview, echocardiography findings and laboratory estimation of cTnl.

A total 60 patients and 30 healthy control subjects were investigated for cTnI. cTnl level was within normal physiological limits in all the control subjects. The mean value was $0.02 \pm 00$. The mean cTnI level in aortic stenosis patients was $0.67 \pm 0.81$. In mitral stenosis patients and in patients with both aortic and mitral stenosis cTnl level was also within normal physiological limits. The mean level was $0.02 \pm 0.21$ and $0.15 \pm 0.50$ respectively. Ejection fraction of all the patients were normal, indicating that cases yet not developed complication (eg; Heart failure). The cTnl in control group and aortic stenosis patients shows significant difference of mean (<0.001). But the cTnl in control group and other groups of patients shows no significant difference of mean (>0.05) cTnl level in aortic stenosis patients increases in absence of heart failure indicating that it can expose cardiomyocyte injury prior to the development of overt Left ventricular dysfunction. So that, serial monitoring of cTnl could help clinicians to give definitive treatment before development of complications.
\end{abstract}

Key words: Cardiospecific Troponin I, Aortic stenosis.

(Bangladesh J Physiol Pharmacol 2009; 25(1\&2) : 4-6)

\section{INTRODUCTION}

Valvular heart disease is a common cardiac disease in our country. The valvular heart disease which we face in our day to day hospital and private practice is due to chronic sequlae of rheumatic fever. In chronic rheumatic heart disease mitral valve is affected in more than $90 \%$ of cases and aortic valve is the next most frequently affected valve ${ }^{1}$.

In aortic stenosis there occurs obstruction to left ventricular out flow during systole. Pressure gradient across the aortic valve (pressure higher in left ventricle than aorta during systole) causes chronic Lt ventricular pressure overload and compensatory Lt ventricular hypertrophy. Increased wall thickness and decreased cavity size oppose the increased wall stress. The left ventricular hypertrophy initially leads to diastolic

Address of Correspondence: Dr. Nazmun Nahar, Department of Biochemistry, Ibrahim Medical college, Dhaka dysfunction and letter on systolic dysfunction. In the late state, left ventricular systolic function can be reduced as a result of myocardial fibrosis ${ }^{2}$. The sequence of cardiac decompensation begins with ventricular dilatation, which further raises wall stress, leading to increased left ventricular hypertrophy and probably reduced blood flow to the hypertrophied myocardium, in term leading to ischemia with reduced left ventricular ejection fraction. Furthermore, aortic stenosis is itself associated with $50 \%$ increased risk of cardiovascular mortality and myocardial infarction ${ }^{3}$.

In mitral stenosis obstruction of blood flow from Lt. atria to Lt. ventricle during diastole, causing increased pressure in the Lt. atrium, pulmonary capillaries and eventually pressure increases in the right side of the heart. As valve area gets smaller, conditions which increases valve flow from Lt. atria to Lt. ventricle (exercise, tachycardia) results in an increase in Lt. atrial pressure and worsen the condition. 
Increase Lt. atrial pressure'!Pul. HTN'!RV pressure overload'!RV failure \& tricuspid regurgitation 4

Lt. ventricular systolic dysfunction and heart failure predict poor prognosis including a less favorable outcome after valve replacement in aortic stenosis. The onset of heart failure is preceded by structural and functional alterations in the heart muscle with degeneration and death of the cardiac myocyte ${ }^{5}$.Disease of the heart valves may progress with time and selected patients require regular review, usually every 1 or 2 years, to ensure that deterioration is detected before complication such as heart failure ensue ${ }^{1}$. Detection of ongoing myocardial injury before the outbreak of overt Lt. ventricular dysfunction could help promote earlier surgery in patients without symptom or with vague symptom.

Troponin I, a protein molecule that plays an essential role in the contraction of the striated muscle. cTnl has been established as reliable and highly heart specific markers of myocyte injury. Their background concentrations in the circulation are normally undetectable or very low and they are therefore sensitive to even minor heart muscle damage. Measuring circulating cardiac Troponinl would help expose ongoing silent myocyte damage in aortic stenosis ${ }^{6}$. cTnl was elevated even in the absence of heart failure indicating that it can expose cardiomyocyte injury prior to the development of overt Lt. ventricular dysfunction. Serial monitoring of cTnl during follow up of asymptomatic aortic stenosis will show whether cTnl can assist in the timing of therapeutic interventions.

The aim of the study was to explore the relationship of serum cTnl and aortic stenosis. So that it will help in the detection of ongoing myocardial injury in aortic stenosis patient before the outbreak of overt Lt. ventricular dysfunction which will help to promote earlier surgery in patients without symptom or with vague symptom.

In MS no significant cardiac ischaemia develops that causes release of cTnl from cardiac myocytes. So, study of relationship between cTnl and aortic stenosis will be more significant and informative then study of relationship between cTnl and mitral stenosis.

\section{PATIENTS AND METHODS}

20 patients ( 2 male and 18 female) between the age ranges of 5-60 years were selected having aortic stenosis, 20 patients (3male \& 17 female) between the age ranges of 18-60 years were selected having mitral stenosis, \&20 patients (1male and 19 female) between the age ranges of 16-65 years were selected having both aortic and mitral stenosis, that were confirmed by echocardiography. All the patients came to the out patient department of NICVD with mild symptoms such as palpitation, chest pain, and exertional dyspneoa. Ischemic heart disease was excluded by
Echocardiography. 30 control subjects ( 5 male and 25 female) between the age ranges of 5-60 years were selected randomly. A blood sample for determination of cTnl was obtained by vein puncture. Micro particle enzyme immune assay was done for the quantitative determination of cTnl.

Data are presented as mean \pm SD. Mann Whitney $U$ test was done as the test of significance. A probability value of $p<0.05$ was considered significant. All calculations were done with SPSS system 10.0.

\section{RESULTS}

cTnl level was within normal physiological limits in all the control subjects. The mean value was $0.02 \pm 0.00$. Among the patients of aortic stenosis cTnl was undetectable in two patients, in two patients there was detectable cTnl but it was within normal physiological limits, and another sixteen patients had elevated levels of cTnl. The mean cTnl level in aortic stenosis patient was $0.67 \pm 0.81$, having significant difference with control subjects $(p<0.001)$. The mean conc of $c T n l$ in mitral stenosis patients and in patients with both aortic and mitral stenosis were $0.02 \pm 0.21 \mathrm{ng} / \mathrm{ml}$ and $0.15 \pm 0.50 \mathrm{ng} /$ $\mathrm{ml}$ respectively, both having no significant difference with the control subjects ( $p>0.05)$.

The normal ejection fraction is e" $55 \%$. The ejection fraction of cases and control subjects shows no significant difference of mean.. This indicates that cases yet not develop complications, such as heart failure (as shown by lowered ejection fraction).

Table I

Ejection fraction and cTnl in study subject.

\begin{tabular}{lcc}
\hline Groups & cTnl(ng/ml) & Ejection fraction \\
& Mean $\pm \mathrm{SD}$ & Mean $\pm \mathrm{SD}$ \\
\hline Control subjects & $0.02 \pm 0.00$ & $65.25 \pm 3.25$ \\
Aortic stenosis patients & $0.67 \pm 0.81$ & $63.10 \pm 6.33$ \\
Mitral stenosis patients & $0.02 \pm 0.21$ & $60.70 \pm 7.96$ \\
\hline
\end{tabular}

Table-II

Comparison of cTnl between case and control.

\begin{tabular}{lcc}
\hline Groups & cTnl $(\mathrm{ng} / \mathrm{ml})$ & Mean \pm SD \\
Level of significance & (P value) & \\
\hline AS patient vs & $0.67 \pm 0.81 \mathrm{vs}$ & 0.001 \\
control & $0.02 \pm 0.00$ & \\
MS patient vs & $0.02 \pm 0.21 \mathrm{vs}$ & 0.448 \\
control & $0.02 \pm 0.00$ & \\
AS with MS patient vs & $0.15 \pm 0.50 \mathrm{vs}$ & 0.067 \\
control & $0.02 \pm 0.00$ & \\
\hline
\end{tabular}

Data are presented as mean \pm SD. Mann Whitney $U$ test was done as the test of significance. 


\section{DISCUSSION}

It is evident from the findings of present study that there is a significant higher level of serum cTnl in aortic stenosis patients with normal ejection fraction. The survival rates of the patients with asymptomatic aortic stenosis patients are nearly normal, until the symptoms of angina, syncope or heart failure develops. The presence of symptoms of heart failure in patients of aortic stenosis causes a bad prognosis within a short period of time (mean survival<2years) ${ }^{7}$. We found that cTnl elevated in the absence of heart failure indicating that it can expose cardiomyocyte injury prior to the development of overt Lt. ventricular dysfunction. So that, serial monitoring of cTnl could help clinicians to give definitive treatment before development of complications.

Cardiac Troponinl I have been established as reliable and highly heart specific markers of myocyte injury. Their background conc. in the circulation are normally undetectable or very low (normal level is $0.00-0.05 \mathrm{ng} /$ $\mathrm{ml}$ ) and they are therefore sensitive to even minor heart muscle damage ${ }^{6}$. The triggers of myocyte death in aortic stenosis have not been detailed, the possible path physiology is that in aortic stenosis there occur narrowing of aortic valve which causes decreased blood flow from the left ventricle to the aorta. This increases workload of the workload of the Lt. Ventricle. This forces the left ventricle to squeeze harder, as a result the walls become thicker in time and left ventricular hypertrophy develops. The hypertrophied Lt. ventricular muscle mass elevates myocardial oxygen requirements. Even in the absence of obstructive coronary artery disease there may be interference with coronary blood flow. This is because of the compression of the coronary arteries by the hypertrophied myocardium. The coronary arteries that give nutrition to the heart muscle with blood and oxygen arise just valve may not get enough blood to adequately supply the heart muscle ${ }^{8}$. This in turn, results in the relative ischemia of the Lt. ventricular myocardium and consequently death of the cardiac myocyte ultimately leads to the development of depressed systolic function and heart failure 6 . However, it is noted that circulating cTnl was undetectable in two of our patients with severe aortic stenosis. This suggests that myocytes injury can be intermittent and may therefore escape detection.

In mitral stenosis there occurs decreased blood flow from the Lt. atrium to the Lt. ventricle, which causes increased workload of the Lt. atrium. Lt. atrium squeezes harder to deliver blood to the Lt. ventricle. As a result Lt. atrial hypertrophy develops. But the Lt. atrium is a small structure and its blood and oxygen requirement is very small. So that although Lt. atrial hypertrophy develops in mitral stenosis cardiac ischaemia does not develop.

In patients suffering from both aortic and mitral stenosis blood flow from the Lt. atrium to the Lt. ventricle is reduced. As a result, although the patient has co existing aortic stenosis left ventricle can deliver its content blood through the stenosed aortic valve without increasing its workload. So that, in patients with both aortic and mitral stenosis left ventricular hypertrophy does not develops which prevents the development of cardiac ischemia.

An important limitation of work this have financial constrain in serial measurement of cTnl and left ventricular functions. Therefore, the true predictive value of circulating cTnl could not be studied. Only serial monitoring of cTnl during follow up of asymptomatic aortic stenosis will show whether cTnl can assist in the timing of therapeutic interventions.

From present study findings we can conclude that circulating cTnl concentrations are frequently detectable and elevated in patients with severe aortic stenosis even in the absence of heart failure. Circulating cTnl deserves a potential warning signal in patients with severe but still asymptomatic aortic stenosis.

\section{REFERENCES}

1. Bloomfield, Bradbury A, Cumming AD, Stewart LH; cardiovascular disease; in editors-Boon, College,Walker, Hunter; In Davidson's principle and practice medicine; $19^{\text {th }}$ edition; Edinberg, Churchill Livingstone Publication; 2005; PP 458-461.

2. Reydberg, Gudmundsson P, Kennedy L, Erdardt L, Willenheimer R; Left arterioventricular plane displacement but not left ventricular ejection fraction is influenced by the degree of aortic stenosis; Heart; 2004:90;1151-1155.

3. Otto Cm, Lind BK, Kitzman DW, Gersh BJ, Siscovick DS; Association of aortic valve stenosis with cardiovascular mortality and morbidity in the elderly; N Engl J Med; 1999; 341; $142-7$.

4. Kenneth Korr; General principles of valvular malfunction; 2001;Available from;file:///1IDocouments and settings/ Douglas burtt/My—uments/Teaching/Bio-Med 281/lecturer/ handout 2.htmt (1 to 15). (5\5।2006)

5. Hein S, Arnon E, Kostin S, Schonburg M, Elsassen A, Polyakova V, Erwin P, Baucu, Klovekomn WP, Schapen J; Progression from compensated hypertrophy to failure in the pressure overload human heart, structural deteriuoration and compensatory mechanisms; Circulation; 2003; 107; 984-91.

6. Kupari M, Erilsson S, Turlo H, Lommi J and Petterson K; Leakage of cardiac troponin I in aortic valve stenosis; Journal of internal medicine; 2005;258;231-237.

7. Park $\mathrm{MH}$; Timely intervention of asymptomatic aortic stenosis; Postgraduate medicine; 2001; 110. Mayofoundation; Effects of congenital aortic stenosis; 2005; Available from; http:/www.Mayoclinic. Orglcongenitalaortic stenosis jaxleffects. html. (1/5l2006). 